\title{
A New Concurrent Chemotherapy with Vinorelbine and Mitomycin C in Combination with Radiotherapy in Patients with Locally Advanced Squamous Cell Carcinoma of the Head and Neck
}

\author{
Ralf Wilkowski ${ }^{a}$ Sophia Pachmann ${ }^{a}$ Beatrice Schymura ${ }^{a}$ Marc Dellian ${ }^{b}$ Andreas Schalhorn ${ }^{c}$ \\ Eckhart Dühmke ${ }^{a}$ \\ a Klinik und Poliklinik für Strahlentherapie und Radioonkologie, \\ b Klinik für Hals-, Nasen- und Ohrenkranke, \\ c Medizinische Klinik III, Ludwig-Maximilians-Universität, München, Germany
}

\section{Key Words}

Head and neck cancer, advanced - Chemotherapy, concurrent - Vinorelbine - Mitomycin C · Radiotherapy

\section{Summary}

Objective: The purpose of this pilot study was to evaluate the feasibility and toxicity of concurrent chemotherapy with vinorelbine and mitomycin $\mathrm{C}$ in combination with accelerated radiotherapy (RT) in patients with locally advanced cancer of the head and neck. Patients and Methods: Between January 2003 and March 2004, 15 patients with T4/N2-3 squamous cell carcinoma (12/15) and with N3 cervical lymph node metastases of carcinoma of unknown primary $(3 / 15)$ were treated with chemotherapy and simultaneous accelerated RT. Results: 11 patients completed therapy without interruption or dose reduction. Grade 3-4 acute mucosal toxicity was observed in 9/15 patients, grade 4 hematologic toxicity in $6 / 15$ patients. At a median follow-up of 7.5 months, 2 patients have died of intercurrent disease, 2 patients have experienced local relapse; 5 patients are alive with no evidence of disease at the primary tumor site. Discussion: The described regimen is highly effective, but led to remarkable side effects.
Schlüsselwörter

Kopf-Hals-Karzinom, fortgeschrittenes - Chemotherapie, simultane · Vinorelbin - Mitomycin C . Strahlentherapie

\section{Zusammenfassung}

Hintergund: Ziel dieser Pilotstudie war es, die Durchführbarkeit und Toxizität einer Chemotherapie mit Vinorelbin und Mitomycin C in Kombination mit einer simultanen Strahlentherapie (RT) bei Patienten mit lokal fortgeschrittenen Kopf-Hals-Tumoren zu evaluieren. Patienten und Methoden: Zwischen Januar 2003 und März 2004 wurden 15 Patienten mit T4/N2-3 Plattenepithelkarzinomen (12/15) oder mit zervikalen N3-Lymphknotenmetastasen bei unbekanntem Primärtumor (3/15) einer Chemotherapie und einer akzelerierten RT unterzogen. Ergebnisse: Bei 11 Patienten konnte die Radiochemotherapie ohne Unterbrechung oder Reduktion der Zielvolumendosis durchgeführt werden. Eine akute Grad 3-4 Mukositis war bei 9/15 Patienten, eine hämatologische Toxizität Grad 4 bei 6/15 Patienten nachweisbar. Im medianen Beobachtungszeitraum von 7,5 Monaten waren 2 Patienten an Begleiterkrankungen verstorben und 2 entwickelten ein Lokalrezidiv. 5 Patienten zeigten eine anhaltende komplette Remission. Diskussion: Die verabreichte Radiochemotherapie ist eine hoch wirksame Therapie für diese Patienten, wird aber von wesentlichen akuten Nebenwirkungen begleitet.

\begin{tabular}{ll}
\hline KARGER & ( ) 2005 S. Karger GmbH, Freiburg \\
$\begin{array}{l}\text { Fax +497614520714 } \\
\begin{array}{l}\text { E-mail Information@Karger.de } \\
\text { www.karger.com }\end{array}\end{array}$ & $\begin{array}{l}\text { Accessible online at: } \\
\text { www.karger.com/onk }\end{array}$ \\
\end{tabular}

Dr. Ralf Wilkowski

Klinik und Poliklinik für Strahlentherapie und Radioonkologie

Ludwig-Maximilians-Universität München

Marchioninistr. 15, 81377 München, Germany

Tel. +49 89 7095-3770, Fax -3760

E-mail ralf.wilkowski@med.uni-muenchen.de 
Carcinoma of the head and neck is a frequent disease - each year approximately 53,000 new cases are diagnosed in Western Europe, usually associated with the abuse of alcohol and nicotine [1]. Most of the carcinomas are locally advanced at presentation. While in early stages many patients can be treated in curative intention and the 5-year overall-survival is as high as $70-90 \%$, locally advanced disease is still difficult to treat.

In general, surgery (or radiotherapy, RT) is the favored treatment modality for smaller lesions (T1/T2), whereas more advanced stages (T3/T4, III/IV) are better treated with combined surgery (if possible) and RT [2]. Platinum-based concomitant chemotherapy and RT is superior to conventional RT alone in improving survival in locally advanced squamous cell carcinoma of the head and neck (SCCHN) [3]. The use of altered fractionation schedules (e.g. twice daily radiotherapy, 9-10 fractions per week) has allowed a significantly greater proportion of patients with advanced head and neck tumors to be cured with organ preservation [4]. Yet, even in relatively favorable cases (e.g. T3), local relapses (30-60\%) occur despite all advances in treatment modalities including high doses of radiotherapy and chemotherapy [5]. 20\% of patients with stage III/IV experience treatment failure due to distant metastases. Improvements in loco-regional control and disease-free survival rates are often obtained at the price of increased acute and late toxicity.

Thus, there is a clear need for further improvement of the therapeutic outcome in locally advanced SCCHN. Metaanalyses seem to prove that patients with locally advanced tumors achieve a modest, but statistically significant survival benefit from concurrent chemo-radiation whereas neoadjuvant and adjuvant chemotherapy did not convey a significant survival advantage [6].

Among chemotherapeutic agents with activity against SC$\mathrm{CHN}$, many drugs have been evaluated including cisplatin and 5-fluorouracil (5-FU). But response rates are moderate and toxicity is increased [7], so research is continued to find effective and well tolerable drugs that can be used in combination with radiotherapy. Taxanes, topoisomerase I inhibitors and nucleoside analogues like gemcitabine, which might be potent antitumor agents have been tested in recent phase I-II studies with moderate to promising results. Treatment costs have also to be included in considerations for treatment planning.

Vinorelbine, a semisynthetic vinca alkaloid, acting through disorganisation of microtubules during mitosis, is used as a single agent in the treatment of advanced breast cancer, where it induces a response rate of approximately $20 \%[8,9]$. Preclinical studies indicated a role for vinorelbine as a radiosensitizer. A series of published studies have shown that the use of vinorelbine and other drugs [10] such as cisplatin and ifosfamide followed by carefully planned radiotherapy is both adequately tolerated and able to achieve high response rates together with improved survival in patients with locally advanced NSCLC [11].

Mitomycin $\mathrm{C}$ is frequently used for this disease entity. Given
Table 1. Patient characteristics

\begin{tabular}{|c|c|}
\hline \\
\hline \multirow[t]{2}{*}{ Median age, years (range) } & $58(45-71)$ \\
\hline & $\mathrm{n}(\%)$ \\
\hline Patients & $15(100)$ \\
\hline Distant metastases & $2(13)$ \\
\hline \multicolumn{2}{|l|}{ Histology } \\
\hline Squamous cell carcinoma $\mathrm{G} 2^{\mathrm{a}}$ & $7(47)$ \\
\hline Squamous cell carcinoma G3 ${ }^{\mathrm{a}}$ & $7(47)$ \\
\hline First-line therapy, n & $15(100)$ \\
\hline \multicolumn{2}{|l|}{ Predominant site of disease } \\
\hline Oropharynx & $2(13)$ \\
\hline Hypopharynx & $2(13)$ \\
\hline More than one region & $6(40)$ \\
\hline Larynx & $1(7)$ \\
\hline Nasopharynx & $1(7)$ \\
\hline N3 cervical lymph nodes (CUP) & $3(20)$ \\
\hline $\begin{array}{l}\text { a One patient: squamous cell carcin } \\
\text { classified. }\end{array}$ & ma, not \\
\hline
\end{tabular}

concomitantly to radiotherapy mitomycin $\mathrm{C}$ improves longterm tumor control $[12,13]$. In combination with fractionated irradiation, mitomycin $\mathrm{C}$ significantly reduces the risk of local recurrences and inhibits tumor cell repopulation in vivo in fast growing squamous cell carcinoma in mice, thus indicating its function as a radiosensitizer [14]. The combination of mitomycin $\mathrm{C}$ and vinorelbine in patients with metastatic breast cancer was proven effective and well tolerable with response rates of 35-73\% [14-16]. Conti et al. even found response rates of up to $92 \%$ for the treatment of breast cancer for this combination [17].

Our aim was to evaluate the activity and toxicity of an intensified regimen containing vinorelbine and mitomycin $\mathrm{C}$ in combination with accelerated radiotherapy in patients with locally advanced squamous cell carcinoma of the head and neck.

\section{Patients and Methods}

\section{Patient Characteristics}

From January 2003 to March 2004, 15 male patients with locally advanced T4/N2-3 SCCHN and N3 cervical lymph node metastases of carcinoma of unknown primary (CUP) were treated with accelerated radiotherapy (57.6 Gy over 5 weeks, boost of $14.0 \mathrm{~Gy}$ ) and concurrent chemotherapy with vinorelbine $\left(25 \mathrm{mg} / \mathrm{m}^{2}\right.$ on day $\left.1,8,22,29\right)$ and mitomycin $\mathrm{C}\left(8 \mathrm{mg} / \mathrm{m}^{2}\right.$ on day 1 and 29). 12/15 patients (80\%) with SCCHN had T4N+ disease, $3 / 15$ patients $(20 \%)$ had N3 cervical lymph nodes of carcinoma of unknown primary and had been judged unresectable. None of the patients had received radiotherapy before. 2 patients had distant metastases (1 lung, 1 lung and liver). 4 patients suffered from severe other diseases: 1 patient with HIV-infection had been under antiviral treatment for 15 years, 1 patient suffering from pemphigus required constant therapy with steroids. 1 patient had liver cirrhosis (Child A). 1 patient suffering from rheumatoid arthritis had been pretreated with low doses of methotrexate for months. All patients had a history of alcohol and/or nicotine 


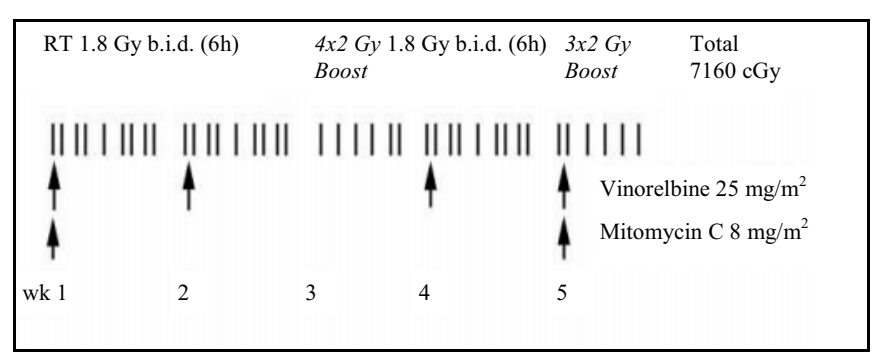

Fig. 1. Treatment plan

abuse. 2 patients had required psychological assistance during previous treatment due to alcoholic delirium.

All patients had histologically confirmed squamous cell carcinoma. In all patients computer tomography and/or magnetic resonance imaging scans of the head and neck region as well as CT scans of the lung and CT scans of the abdomen and/or liver sonography were performed to evaluate distant metastases before the start of therapy. All patients had a Karnofsky performance status $>60 \%$, white blood count $>3500 / \mathrm{mm}^{3}$, platelet count $>100,000 / \mu \mathrm{l}$, serum creatinine level inside normal range and bilirubin $<1.5 \mathrm{mg} / \mathrm{d}$ (table 1$)$.

\section{Treatment and Evaluation}

Chemotherapy. Vinorelbine was given intravenously at the dose of $25 \mathrm{mg} / \mathrm{m}^{2}$ on day $1,8,22,29$, mitomycin $\mathrm{C}$ at the dose of $8 \mathrm{mg} / \mathrm{m}^{2}$ on day 1 and 29 (fig. 1). For prevention of anaphylactoid reactions through mitomycin $\mathrm{C}$ prednisone (i.v.) was given prior to application. All patients received prophylaxis of mucositis, including aqueous mouth rinse containing chlorhexidine gluconate, dexpanthenol solutions and oral amphotericin B. Oral fluconazol was given in case of grade IV neutropenia or in case of grade III or IV mucositis; in case of febrile neutropenia, intravenous antibiotic therapy was started with tazobactam/piperacillin and was adapted to antibiotic resistance testing if possible. The patient's weight was monitored weekly, and nutritional support with parenteral nutrition was planned when weight loss would exceed approximately $10 \% .2$ patients had a feeding tube placed before treatment. Toxicity was categorized according to WHO criteria. Hematological toxicity was assessed by repeated blood counts at least once a week.

Radiotherapy. All radiation fields were delivered with $6 \mathrm{MV}$ photons by linear accelerator; all patients received 3D plans to assess dose homogeneity in the target volume. Patients were treated in supine position using individualized head immobilization devices. The target volume in cluded the primary tumor area and local-regional lymph nodes. For radiotherapy we used a regimen very well established for years in our department: The prescribed dose for tumor region and clinically involved lymph nodes was $57.6 \mathrm{~Gy}$. All 15 patients were treated with accelerated radiotherapy twice daily with fractions of 1.8 Gy each, separated by $6 \mathrm{~h}$ on Monday, Tuesday, Thursday and Friday (only one fraction on Wednesdays). After $32.4 \mathrm{~Gy}$, an $8.0 \mathrm{~Gy}$ boost was given only to the regions of macroscopic tumor at fractions of 2.0 Gy once daily. Another boost of $6.0 \mathrm{~Gy}$ to the same regions was given at the end of therapy. The cumulative dose of those patients was 71.6 Gy (fig. 1). Uninvolved lymphatic regions (neck and supra-/infraclavicular regions) were treated with a dose of $52.2 \mathrm{~Gy}$. Multileaf collimators were used to limit irradiation to the surrounding normal tissues. Maximum spinal cord dose was limited to $<40.0$ Gy. Electron beams were used if necessary to achieve the prescribed dose in the nuchal and paravertebral regions. The dose was calculated according to ICRU 50/70.

Response. Primary response was evaluated by clinical examination and CT scan imaging approximately 3 months after completion of therapy, additional evaluation was done after 6 and 12 months, if possible. Complete response was defined as the disappearance of all local disease sites (pri-
Table 2. Acute toxicity

\begin{tabular}{|c|c|c|c|c|}
\hline \multirow[t]{2}{*}{ Toxicity } & \multicolumn{4}{|l|}{ Grade } \\
\hline & I & II & III & IV \\
\hline Mucositis, $\mathrm{n}$ & $2(13 \%)$ & $4(27 \%)$ & $7(47 \%)$ & $2(13 \%)$ \\
\hline Leucopenia, n & $2(13 \%)$ & $3(20 \%)$ & $4(27 \%)$ & $6(40 \%)$ \\
\hline Dysphagia, n & $1(7 \%)$ & $2(13 \%)$ & $12(80 \%)$ & - \\
\hline
\end{tabular}

mary tumor, local lymph node metastases). Partial response was defined as a decrease of $50 \%$ or more in the sum of the largest perpendicular diameters of measurable lesions, with no appearance of new lesions and no progression of any lesion. Stable disease was defined as decrease of less than $50 \%$ with no increase in measurable tumor volume.

\section{Results}

\section{Acute Toxicity}

All patients had mild to severe mucositis; 2 (13\%) patients experienced grade IV, 7 (47\%) patients grade III mucositis; $6(40 \%)$ patients had grade IV and $4(27 \%)$ patients had grade III leukopenia. 12/15 (80\%) patients required parenteral nutrition (table 2). 4/15 (27\%) patients required G-CSFsupport. $4 / 15(27 \%)$ patients required red blood cell transfusions. 4/15 (27\%) patients were treated with parenteral antibiotics because of febrile neutropenia. No patient required platelet transfusions. Interruption of radiotherapy for 1-3 days was necessary in 3 patients because of infection, low WBC counts or noncompliance. No patient had cardiac toxicity or neurotoxicity. No patient complained of nausea or vomiting, no patient experienced pulmonary toxicity, alopecia or other, non-hematologic, not mucosa-associated toxicity.

\section{Late Toxicity}

All patients experienced mild cutaneous fibrosis and moderate xerostomia. $3 / 15$ patients $(20 \%)$ experienced severe late toxicity: 1 patient had perichondritis, requiring hospitalization and parenteral nutrition for several days; 2 patients complained of dysphagia through stenosis of the upper esophagus, leading to significant weight loss and placement of a feeding tube 6 months after completion of radiochemotherapy in 1 patient and to necessity of repeated dilatation treatment in the other patient (table 3).

\section{Tumor Response}

After a median follow-up of 7.5 months 5 patients (33\%) achieved complete remission and 8 patients (53\%) achieved a partial remission as determined 3 months after completion of treatment (table 4). The histological grading had no influence on response rates. $1 / 8$ patients with a partial remission experienced relapse in a nuchal lymph node after 8 months and $1 / 8$ patients showed a local recurrence in the region of the hypopharynx, where the maximum dose had been applied. 
Table 3. Late toxicity

\begin{tabular}{lc}
\hline Toxicity & Patients, n \\
\hline Cutanous fibrosis, mild & $15(100 \%)$ \\
Xerostomia, moderate & $15(100 \%)$ \\
Perichondritis & $1(7 \%)$ \\
Stenosis of the upper esophagus & $2(13 \%)$ \\
\hline
\end{tabular}

Table 4. Tumor response after a median months follow-up of 7.5

\begin{tabular}{ll}
\hline Response & Patients, $\mathrm{n}$ \\
\hline Complete response & $5(33 \%)$ \\
Partial response & $8(53 \%)$ \\
Stable disease & $2(13 \%)$ \\
\hline
\end{tabular}

Distant failure alone occurred in 1/12 patients (in addition to 2 patients having already known metastases). One patient died of intercurrent infection 4 months after completion of treatment. Another patient died of gastro-intestinal bleeding two months after completion of treatment. At the time of evaluation (March 2004), 8/15 patients were alive with no evidence of disease at the primary tumor site.

\section{Discussion}

In a meta-analysis Pignon et al. [18] showed that benefit in overall survival and local control is greatest with concomitant chemotherapy and altered fractionated radiotherapy. To our knowledge, this is the first reported experience evaluating the tolerability and efficacy of concurrent chemotherapy with vinorelbine and mitomycin $\mathrm{C}$ and accelerated radiotherapy in patients with locally advanced SCCHN and N3 cervical lymph node metastases of CUP. The unique features and potential advances associated with this chemoradiation regimen are local and systemic synergistic anti-tumor effects of two chemotherapeutic agents and radiation therapy. The use of accelerated RT shortens overall treatment time and enables radiation dose escalation with associated improved local tumor control.

Compared with previously reported chemoradiation experiences for SCCHN, our regimen of accelerated RT and chemotherapy with vinorelbine and mitomycin $\mathrm{C}$ has been associated with severe but similar side effects. Reported studies have shown grade III/IV acute toxicity rates of $>50 \%$ and mortality rates up to $8 \%$ [19-21]. Specific toxicities and rates include grade IV hematologic toxicity in 10-55\% [20-22], grade IV mucosal toxicity in 13-18\% [20-22] and grade III/IV neurologic toxicity in $2-6 \%$ of patients $[23,24]$. In comparison with a prospective, randomized study of Budach et al. [25], who combined 5-FU and mitomycin $\mathrm{C}$ with a hyperfractionated accelerated radiation therapy, the rate of grade III/IV mu- cositis $(65.7 \%)$ was similar to our results $(60 \%)$. Grade III leucopenia was observed in $8.5 \%$, no patient showed grade IV leucopenia, whereas in our study the rate of grade III/IV leucopenia was very high (27 and 40\%).

Harrison et al. [26] treated 52 patients with unresectable tumors of the head and neck region with RT (accelerated fractionation, total $70 \mathrm{~Gy}$ in concomitant-boost technique) and chemotherapy (cisplatin or mitomycin C). They found mitomycin $\mathrm{C}$ to be too myelosuppressive and therefore eliminated this substance from their program.

Another study, the IAEA multicentre randomised trial, reports very low hematological side effects $(<5 \%$ grade III/IV) of mitomycin $\mathrm{C}$ (one single injection of $15 \mathrm{mg} / \mathrm{m}^{2}$ ) in combination with conventional fractionated radiotherapy in patients with locally advanced head and neck cancer [27]. Our grade IV hematologic toxicity rate of $40 \%$ seems to be unacceptably high, so the chemotherapy dose was reduced for the recently started phase II study.

Two accelerated schedules, CHART [28] and RTOG 9101 [29] have been associated with a significant reduction in the incidence of late normal tissue morbidity compared with conventional fractionation [1]. However, there is a significant increase in the incidence of fibrosis in the accelerated fractionation arm of the EORTC 22851 trial, supported by evidence from other clinical and experimental studies. In our patients, severe late toxicity consisted of one case of perichondritis requiring hospitalization for several days and in two cases of stenosis of the upper esophagus through fibrosis.

Other treatment strategies, such as hyperfractionated accelerated radiotherapy combined with intra-arterial cisplatin infusions [5] have shown promising results, but can only be performed in few patients with limited tumor extension. Selective lymph node dissection after accelerated chemoradiation with mitomycin C/5-FU to a dose of $70.6 \mathrm{~Gy}$ is likely to contribute to loco-regional tumor control in advanced head and neck cancer patients, as reported by Hehr et al. [30]. Our response rate of $86 \%$ in a highly unfavorable patient collective can not be interpreted yet due to short follow-up time but seems to be comparable or even more favorable than other regimens with intensive chemoradiation. A prospective randomized trial is necessary to evaluate the efficacy of this treatment regimen. In conclusion, chemoradiotherapy with vinorelbine and mitomycin $\mathrm{C}$ and accelerated RT as used in our patients was associated with a high response rate but also with a high rate of grade III/IV acute toxicity concerning mucositis and low white blood cell counts. Our findings appear comparable to previously reported chemoradiation regimens in similar patients. The described regimen with less intensive chemotherapy is currently under study with the intent of optimizing maximally tolerable and efficacious therapy in patients with locally advanced SCCHN. To evaluate pathologic response and to further improve the prognosis of those patients, surgical resection after radiochemotherapy is another treatment option that is discussed individually for every patient. 


\section{References}

1 Bernier J, Bentzen SM: Altered fractionation and combined radio-chemotherapy approaches: pioneering new opportunities in head and neck oncology. Eur J Cancer 2003;39:560-571.

2 Wendt TG, Bank P: Prognostic factors in squamous cell carcinoma of the head and neck. Onkologie 2002;25:208-212.

3 Browman GP, Hodson DI, Mackenzie RJ, Bestic N, Zuraw L: Choosing a concomitant chemotherapy and radiotherapy regimen for squamous cell head and neck cancer: a systematic review of the published literature with subgroup analysis. Head Neck 2001;23:579-589.

4 Fu KK, Pajak TF, Trotti A, Jones CU, Spencer SA, Phillips TL, Garden AS, Ridge JA, Cooper JS, Ang KK: A Radiation Therapy Oncology Group (RTOG) phase III randomized study to compare hyperfractionation and two variants of accelerated fractionation to standard fractionation radiotherapy for head and neck squamous cell carcinomas: first report of RTOG 9003. Int J Radiation Oncology Biol Phys 2000;48:7-16.

5 Regine WF, Valentino J, John W, Storey G, Sloan D, Kenady D, Patel P, Pulmano C, Arnold SM Mohiuddin M: High-dose intra-arterial cisplatin and concurrent hyperfractionated radiation therapy in patients with locally advanced squamous cell carcinoma of the head and neck: report of a phase II study. Head Neck 2000;22:543-549.

6 Pouillart P, Hoang HT, Brugerie E: Sequential administration of two oncostatic drugs: study of modalities for pharmacodynamic potentiation. Biomedicine 1974;21:471-479.

7 Munker R, Purmale L, Aydemir Ü, Reitmeier M, Pohlmann H, Schorer H, Hartenstein R: Advanced head and neck cancer: long-term results of chemoradiotherapy, complications and induction of second malignancies. Onkologie 2001;24:553-558.

8 Budach W, Paulsen F, Welz S, Classen J, Scheithauer H, Marini P, Belka C, Bamberg M: Mitomycin $\mathrm{C}$ in combination with radiotherapy as a potent inhibitor of tumour cell repopulation in a human squamous cell carcinoma. Br J Cancer 2002; 86:470-476.

9 Gasparini G, Caffo O, Barni S, Frontini L, Testolin A, Guglielmi RB, Ambrosini G: Vinorelbine is an active antiproliferative agent in pretreated advanced breast cancer patients: a phase II study. J Clin Oncol 1994;12:2094-2101.

10 Degardin M, Bonneterre J, Hecquet B, Pion JM, Adenis A, Horner D, Demaille A: Vinorelbine (navelbine) as a salvage treatment for advanced breast cancer. Ann Oncol 1994;5:423-426.

11 Gralla R, Harper P, Johnson S, Delgado FM: Vinorelbine (navelbine) in the treatment of nonsmall-cell lung cancer: Recent developments in combination chemotherapy and radiotherapy. Ann Oncol 1999;10 (Suppl 5):S47-51.
12 Dobrowsky W, Naude J: Continous hyperfractionated accelerated radiotherapy with/without mitomycin $\mathrm{C}$ in head and neck cancers. Radiother Oncol 2000;57:119-124.

13 Haffty BG, Son YH, Papac R, Sasaki CT, Weissberg JB, Fischer D, Rockwell S, Sartorelli AC, Fischer JJ: Chemotherapy as an adjunct to radiation in the treatment of squamous cell carcinoma of the head and neck: results of the Yale Mitomycin Randomised Trials. J Clin Oncol 1997;15: 268-276.

14 De Placido S, Lauria R, Perrone F, Vernaglia Lombardi A, Carlomagno C, Varriale E, Costanzo R, Leo L, De Laurentiis M, Bianco AR: Vinorelbine + mitomycin $\mathrm{C}$ as a second-line treatment of metastatic breast cancer: a two-stage phase 2 study. Oncology 2000;58:8-14.

15 Vici P, Di Lauro L, Carpano S, Amodio A, Pignatti F, Casali A, Conti F, Lopez M: Vinorelbine and mitomycin $\mathrm{C}$ in anthracyclin-pretreated patients with advanced breast cancer. Oncology 1996;53:16-18.

16 Colleoni M, Manente P, Stocker J, Amor H, Lamon S, Nelli P, Vicario G, Sgarbossa G, Graiff C: Mitomycin and vinorelbine in pretreated breast cancer. Tumori 1997;83:834-836.

17 Conti F, Vici P: Vinorelbine in the treatment of breast cancer: current status and prospectives for the future. Clin Ter 1998;149:61-74.

18 Pignon JP, Baujat B, Bourhis J: Individual patient data meta-analyses in head and neck carcinoma: what have we learnt? Cancer/Radiothérapie 2005; 9:31-36.

19 Vokes EE, Kies M, Haraf DJ, Mick R, Moran WJ, Kozloff M, Mittal B, Pelzer H, Wenig B, Panje W: Induction chemotherapy followed by concomitant chemoradiotherapy for advanced head and neck cancer: impact on the natural history of the disease. J Clin Oncol 1995; 13:876-883

20 Kies MS, Haraf DJ, Athanasiadis I, Kozloff M, Mittal B, Pelzer H, Rademaker AW, Wenig B, Weichselbaum RR, Vokes EE: Induction chemotherapy followed by concurrent chemoradiation for advanced head and neck cancer: improved disease control and survival. J Clin Oncol 1998;16:2715-2721.

21 Siu LL, Czaykowski PM, Tannock IF: Phase I/II study of the capable regimen for patients with poorly differentiated carcinoma of the nasopharynx. J Clin Oncol 1998;16:2514-2521.

22 Koch WM, Lee DJ, Eisele DW, Miller D, Poole M, Cummings CW, Forastiere A: Chemoradiotherapy for organ preservation in oral and pharyngeal carcinoma. Arch Otolaryngol Head Neck Surg 1995; 121:974-980.
23 Shin DM, Glisson BS, Khuri FR, Ginsberg L, Papadimitrakopoulou V, Lee JJ, Lawhorn K, Gillenwater AM, Ang KK, Clayman GL, Callender DL, Hong WK, Lippman SM: Phase II trial of paclitaxel, ifosfamide, and cisplatin in patients with recurrent head and neck squamous cell carcinoma. J Clin Oncol 1998;6:1325-1330.

24 Colevas AD, Busse PM, Norris CM, Fried M, Tishler RB, Poulin M, Fabian RL, Fitzgerald TJ, Dreyfuss A, Peters ES, Adak S, Costello R, Barton JJ, Posner MR: Induction chemotherapy with docetaxel, cisplatin, fluorouracil, and leukovorin for squamous cell carcinoma of the head and neck: a phase I/II trial. J Clin Oncol 1998;16:1331-1339.

25 Budach V, Stuschke M, Budach W, Baumann M, Geismar D, Grabenbauer G, Lammert I, Jahnke K, Stueben G, Herrmann T, Bamberg M, Wust P, Hinkelbein W, Wernecke KD: Hyperfractionated accelerated chemoradiation with concurrent fluorouracil-mitomycin is more effective than doseescalated hyperfractionated accelerated radiation therapy alone in locally advanced head and neck cancer: final results of the radiotherapy cooperative clinical trials group of the German Cancer Society 95-06 Prospective Randomized Trial. J Clin Oncol 2005;23:1125-1135.

26 Harrison LB, Raben A, Pfister DG, Zelefsky M, Strong E, Shah JP, Spiro RH, Shaha A, Kraus DH, Schantz SP, Carper E, Bodansky B, White C, Bosl G: A prospective phase II trial of concomitant chemotherapy and radiotherapy with delayed accelerated fractionation in unresectable tumors of the head and neck. Head Neck 1998;20497-503.

27 Grau C, Prakash Agarwal J, Jabeen K, Rab Khan A, Abeyakoon S, Hadjieva T, Wahid I, Turkan S, Tatsuzaki H, Dinshaw KA, Overgaard J: Radiotherapy with or without mitomycin $\mathrm{c}$ in the treatment of locally advanced head and neck cancer: results of the IAEA multicentre randomised trial. Radiother Oncol 2003;67:1-2.

28 Dische S, Saunders MI, Barrett A: A randomized multicentre trial of CHART versus conventional radiotherapy in head and neck cancer. Radiother Oncol 1997;44:123-136.

29 Poulsen MG, Denham JW, Peters LJ, Lamb DS, Spry NA, Hindley A, Krawitz H, Hamilton C, Keller J, Tripcony L, Walker Q: A randomised trial of accelerated and conventional radiotherapy for stage III and IV squamous carcinoma of the head and neck: a Trans-Tasman Radiation Oncology Group Study. Radiother Oncol 2001;60:113-122.

30 Hehr T, Classen J, Schreck U, Glocker S, Koitschev A, Bamberg M, Budach W: Selective lymph node dissection following hyperfractionated accelerated radio-(chemo-)therapy for advanced head and neck cancer. Strahlenther Onkol 2002;178:363-368. 